\title{
Doğuştan çarpık ayak; deformitelerin yinelemesi
}

\author{
Congenital clubfoot; relapsing of deformities
}

\author{
Cemil Yıldı ${ }^{1}$ İsmail Demirkale ${ }^{2}$ \\ ${ }^{1}$ GATA Ortopedi ve Travmatoloji Anabilim Dalı, Ankara \\ ${ }^{2}$ S.B. Keçiören Eğitim ve Araştırma Hastanesi, Ortopedi ve Travmatoloji Kliniği, Ankara
}

\begin{abstract}
Doğuştan çarpık ayağın (DÇA) konservatif tedavisinde Ponseti metodu altın standart olarak kabul edilmektedir. Düzeltme, koruma ve normal ayakkabı giyme olarak üç aşaması olan bu yöntemin herhangi bir aşamasında yapılacak bir hata, özellikle 1-3 yaş arasında deformitelerin yinelemesi ile sonuçlanır. Ekin ve topuk varusu, sıklıkla koruma aşamasında uygun olmayan ortez kullanımı neticesinde tekrarlayabilir. Sert ve şiddetli DÇA'sı olan ve prematür olup bacak çapı küçük olan çocuklarda, uygun tedavi ve takibe rağmen yineleme gözlenebilir. Ponseti yönteminin kritik basamağı, en az $15^{\circ}$ dorsifleksiyonun sağlanabilmesi için gerekli olan ve olguların \%70-80'inde gereken Aşil tenotomisidir. Art ayak varus deformitesi, subtalar gevşetme ve/ veya lateral kapalı kama kalkaneal osteotomi ile düzeltilir. Önceden cerrahi olarak düzeltilmiş olgularda, cerrahi skar dokusunun retraksiyonu ve persistan kas fibrozisi nedeniyle de deformiteler tekrarlayabilir. Tibialis anterior kası ayağa güçlü bir şekilde supinasyon yaptırıyorsa, 2,5 yaşından sonra üçüncü küneiforma transfer edilir. Nedeni ne olursa olsun, yineleme tespit edildikten sonra mümkün olduğunca konservatif kalınmalıdır. Ebeveynlere, manipülasyon ve alçı uygulamasının tedavinin sadece bir basamağı olduğu, düzelmenin ortezlerle korunması gerektiği anlatılmalıdır.
\end{abstract}

Anahtar sözcülkler: çarpık ayak; doğumsal kusurlar; Ponseti; yineleme
The Ponseti method is accepted as gold standard in the treatment of congenital clubfoot. The method consists of correction, protection and normal shoe wearing, and an error made in any of these stages may result in relapse of the deformities especially in the first 1 to 3 years of age. Equinus and hind-foot varus deformities may relapse mostly at correction phase of the treatment due to improper orthosis wearing. Deformities can recur in children with severe and stiff clubfeet, and premature infants with thin calfs, despite proper treatment and follow-up. The most critical step of Ponseti method is Achilles tenotomy necessary in $70-80 \%$ of cases to obtain at least $15^{\circ}$ of dorsiflexion. Hind-foot varus deformity can be corrected by subtalar release and/ or lateral closing wedge calcaneal osteotomy. Deformities can also relapse after previous surgical management due to persistant muscle fibrosis and scar tissue retraction. If tibalis anterior leads the foot to forceful supination, it can be transferred to the lateral cuneiform after 2.5 years of age. Regardless of the cause, conservative treatment should be initiated, if possible. Parents should be alerted for the protection of the correction by orthosis and they should be informed that manipulation and plaster casting constitute only a stage of the treatment.

Key words: clubfoot; congenital defects; Ponseti; relapsing
$\mathrm{D}$ oğuştan çarpık ayak (DÇA), çoğu çocukta, etiyolojiden bağımsız olarak manipülasyon ve seri alçılama ile başarılı bir şekilde tedavi edilebilmektedir. ${ }^{[1,2]}$ Tedavinin hedefleri; fonksiyonel, ağrısız, mobil ve plantigrad basıp modifiye ayakkabı ihtiyacı olmayan ayak elde etmektir. ${ }^{[3]} 1990$ 'lardan bu yana, Ponseti metodu konservatif tedavide altın standart olarak kabul edilmiştir. ${ }^{[2]}$ Seri manipülasyon ve alçılamalar sonrası deformiteler düzeltildikten sonra, üç ay tam zamanlı, daha sonra üç yaşına dek gece takılacak breysler ile DÇA takip edilir. ${ }^{[4]}$ Ponseti metodunun üç safhası vardır: düzeltme, koruma ve normal ayakkabı giyme. Bu üç fazın herhangi birinde; uygunsuz alçılama, yetersiz tenotomi, yetersiz düzeltme ve uyumsuz ebeveyn gibi nedenlerden dolayı deformiteler yineleyebilir. ${ }^{[5]}$ Ponseti metodunun geniş kabul görmüştür, çünkü ilk aşamada belirgin düzelme edildikten sonra yineleyen deformiteler daha çok görünür hale gelir. Yineleme, genellikle ekin ve topuk varusu olan deformitelerin herhangi birisinin yeniden

- Illetişim adresi: Dr. Cemil Yıldız, GATA Ortopedi ve Travmatoloji Anabilim Dalı, Ankara

Tel: 0536 - 9831135 e-posta: cyorto@yahoo.com drismail@yahoo.com

- Geliș tarihi: 25 Mayıs 2015 Kabul tarihi: 25 Mayıs 2015 
ortaya çıkmasıdır ve bu deformiteler statik değildir. [1,6-9] McKay, bu çocukların, özellikle ayağın hızla büyüdüğü 1-3 yaşta sık olan ve geç ortaya çıkabilecek yineleme ihtimali nedeniyle, okul çağına dek takip edilmesini önermiş; geç yinelemelerin nöromusküler hastalık açısından araştırılması gerektiğini belirtmiştir. ${ }^{[1]}$ Park ve arkadaşları, ortez tedavisi sırasında ya da sonraki yıllık takiplerde, $5^{\circ}$ den daha az dorsifleksiyon, ayak ön kısmında gözlenen adduksiyon veya yürüme sırasında supinasyon ile birlikte veya olmaksızın topuk varusu ortaya çıkmasını, erken yineleme ya da rezidüel deformite olarak tanımlamıştır. ${ }^{[4]}$ Yineleyen olgularda, ayak önünde adduksiyon ve kavus deformitesi genellikle gözlenmezken; tarsal dismorfizm, eklem uyumsuzluğu ve ilerleyici dejenerasyon eşlik edebilir. ${ }^{[2,10]}$

\section{ETIYOPATOGENEZ}

Yinelemenin, deformiteyi başlatan birincil patoloji nedeniyle olduğu düşünülmektedir. ${ }^{[10,11]}$ Daha şiddetli ve sert deformitesi olan çocuklarda ve prematüre olup bacak çapı küçük olanlarda, deformiteler uygun tedaviye rağmen yineleyebilir. ${ }^{[10,12]}$ Benzer şiddette deformitesi olup ebeveynleri sorumlu hareket eden çocuklarda ise, deformitelerin yineleme olasılığı daha düşüktür. Alçı tedavisi ile ayaktaki şekil bozukluğu düzeltilip ortez tedavisine geçildikten sonra, gece ortezlerinin yeterince düzenli kullanılmaması nedeniyle, genellikle 2-4 ay içinde deformitelerin yinelediği görülebilir. ${ }^{[10,13-16]}$ Önceki yüksek yineleme oranlarının aksine, özellikle son 20 yılda ebeveynlerin düzeltme sonrası gece ortezlerinin önemini daha iyi kavramaları nedeniyle, yinelemeler önemli ölçüde azalmıştır. Yürüme çağına dek, Denis Browne ortezinde ayak $70^{\circ}$ dış rotasyonda tutularak topuk varusu, ayak adduksiyonu ve metatarsus adduktusun yinelemesi engellenir. ${ }^{[5,17]}$ Tecrübemize göre tedavi ettiğimiz olgularda, yineleme gördüklerimizin hepsinde, ortez kullanımında uygunsuzluk olduğunu gözlemledik. Özellikle, ortez yazılırken aile eğitiminin çok önemli olduğu unutulmamalıdır. Ortez reçetesi yazarken, ilaç reçetesi yazarken olduğundan çok daha fazla açılamalarda bulunulmalıdır. Tüm ortez tedavisi boyunca, aileler periyodik olarak çağrılmalı ve hem kontrol edilmeli hem de ortezin önemi tekrar tekrar vurgulanmalıdır. Ayrıca, ortez uyumunu arttırmak için biz, farklı ortezler de kullanmaktayız.

Ponseti metodunda, ilk aşamada düzeltilmesi gereken kavus deformitesinin ayak önü supinasyonu ile düzeltilememesi, çarpık ayağın tam olarak düzeltilebilmesini imkansız kılar. Uyumlu olmayan ve yürüme çağındaki çocuklarda, seri manipülasyon ve 2-3 haftalık alçılamada da sorunlar yaşanabilir. Ayrıca, adduksiyon, varus ve ekin deformitelerinin sırayla, ardışık manipülasyonlar ve uzun bacak alçı ile düzeltilmesini takiben, son alçıda pronasyon vermeksizin ayağın $70^{\circ}$ 'ye kadar abduksiyonda tutulması, erken yinelemeyi engelleyecektir. Koopere olmayan ebeveyn varsa, varus ve ayak önü adduksiyonu düzeltildikten sonra, sert ve şiddetli DÇA'da deforme edici güçleri ortadan kaldırarak, yinelemeyi engellemek için tibialis posterior ve fleksör dijitorum longus tenotomileri uygulanabilir. ${ }^{[12]}$

Özellikle tam olarak düzeltilemeyecek şiddette deformitesi olan olgularda, kalıcı ya da yineleyen deformiteler kaçınılmazdır. ${ }^{[2,18]}$ Cerrahi olarak tedavi edilen olgularda ise, yineleme ya da rezidüel deformite görülme oranı $\% 25$ olarak bildirilse de, ikincil düzeltme gereken olgu oranı \%3-5 olarak bildirilmiştir. ${ }^{[2,13,19,20]}$ Özellikle sert deformitesi olan çocuklarda, yineleme nedeniyle ek düzeltici cerrahi girişim ihtiyacı \%20'ye ulaşabilir. ${ }^{[21]}$ Yetersiz düzeltilmiş ya da yinelemiş DÇA deformiteleri erken fark edilmezse yineler; erken tanı ile daha etkili bir tedavi uygulanabilir.

Porecha ve arkadaşları, yinelemenin bir diğer ilginç nedeninin, sol taraf DÇA olduğunda, sağ elini kullanan bir cerrahın tedavi sırasında yeterince güçlü abduksiyon veremeyebilmesi olduğunu belirtmişlerdir. ${ }^{[5]}$ Bununla birlikte, hem tedavinin kalitesinden bağımsız olarak DÇA'nın ciddi bir yineleme eğilimi vardır hem de bazı olgularda yetersiz düzeltilmiş rezidüel ekinovarus görülebilmektedir. ${ }^{[2,10]}$ Willis ve arkadaşları, Ponseti tekniğinin başarısız olduğu durumları araştırdıkları çalışmalarında, Ponseti protokolünün \%10 başarısızlık oranına sahip olduğunu göstermişler ve cerrahın DÇA patogenezini ve doğal seyrini çok iyi bilmesi gerektiği sonucuna varmışlardır. ${ }^{[19]} \mathrm{Haft}$ ve Park, Ponseti metodu sonrası rezidüel deformite ya da yineleme görülme olasılığının \%40'a ulaşabildiğini göstermişlerdir. ${ }^{[4,15]}$ Sonrasında, hastalarının 1/3'ünün tendon transferi, uzatma ya da gevşetme gibi cerrahi girişim gerektirdiğini, ancak Ponseti tekniği sonrası ihtiyaç duyulan bu tür girişimlerin daha basit nitelikte olduğunu belirtmişlerdir. Yineleme sonrası tedavi ihtiyacı, hekim ve ebeveynlerin tedavi sonucu hakkında farklı anlayışta olmaları nedeniyle belirsizdir. Deformitenin şiddetine göre değişmekle birlikte; manipülasyon, alçılama ve fizyoterapinin yanı sıra, 'alakart' tarzda seçici yumuşak doku gevşetmeleri uygulanabilir. ${ }^{[4]}$ Ancak, yineleme teşhisi konulduktan sonra mümkün olduğunca konservatif kalınmalı, gereksiz cerrahi işlemlerden kaçınılmalıdır.

DÇA tedavisi sonrası yineleme, temel olarak iki alt başlık altında incelenebilir: 1) Ponseti uygulanan hastalar ve 2) cerrahi tedavi sonrası ortaya çıkan deformiteler. 


\section{PONSETI METODU ILE TEDAVI EDILEN ÇOCUKLARDA YINELEME}

\section{Ekin Deformitesi}

Yineleme, özellikle art ayakta görülür ve orijinal patolojinin ayak bileği çevresindeki bağlar ve kaslarda yarattığı retraksiyon nedeniyle meydana geldiğine inanılmaktadır. ${ }^{[5,10]} \mathrm{Bu}$ nedenle, Ponseti yönteminin kritik basamağı, en az $15^{\circ}$ dorsifleksiyonun sağlanabilmesi için gerekli olan ve olguların \%70-80'de gereken Aşil tenotomisidir. ${ }^{[12]}$ Ardışık manipülasyonlar ve alçılama sonrası $15^{\circ}$ dorsifleksiyon elde edilemezse, Aşil tenotomisi uygulanır. ${ }^{[5,22]}$ Büyük çocuklarda uzatma, küçük çocuklarda ise perkütan tenotomi uygulanır. ${ }^{[16]}$ Aşilotomi için diğer endikasyonlar; $80^{\circ}$ 'den fazla lateral talokalkaneal açı ve ayak arkası Pirani skorunun 2,5'ten yüksek olmasıdır. ${ }^{[3,23]}$ Beraberinde posterior kapsülotomi ile birlikte posterolateral boğumun gevşetilmesi ile, $30^{\circ}$ 'den fazla dorsifleksiyon elde edilebilir. ${ }^{[12,24]}$ Tecrübemize göre, son 15 yılda Ponseti yöntemi ile tedavi ettiğimiz olguların \%98'inde, mini-insizyon ve aşilotomi uyguladık. Aşilotomi ile ilgili hiçbir komplikasyon izlemedik.

\section{Varus Deformitesi}

Park, posteromediyal insizyondan Vulpius tipi Aşil tendon uzatması yaparken, tibialis posterior tendonunun hipertrofiye ve topuk varusundan sorumlu olduğunu belirtmiştir. ${ }^{[4]}$ Tibialis posterior tendonuna aponevrotik uzatma uygulanabilir. Ayak arkası varus deformitesinin en güvenilir radyolojik bulguları, anterior ve lateral talokalkaneal açılardır. ${ }^{[25]}$ Bu deformite, subtalar gevşetme ve/veya lateral kapalı kama kalkaneal osteotomi ile düzeltilir. Ancak, bu prosedür topuk yüksekliğini azaltıp lateral sıkışmaya neden olabileceğinden, topuk pozisyonu açık kama osteotomi ya da lateral deplasman osteotomisi kullanılabilir. ${ }^{[2]} \mathrm{Bu}$ olgularda, Lisfrank hattı boyunca yapılacak kapsülotomiler, ileride sertlik ve ağrıya neden olabilir. ${ }^{[26]}$

\section{Adduksiyon Deformitesi}

Olguların yaklaşık beşte birinin ayak ön kısmında, manipülasyon ve 2-3 kez alçı tedavisine cevap veren, $20^{\circ}$ 'den az adduksiyon gözlenebilir. Park, yineleme tespit ettikleri tüm hastalara abduktor hallusis kasının miyofasyal gevşetmesini uygulamış; bazı hastalarda mediyal eklem kapsülotomisi ve K-teli ile tespit gerektiğini belirtmiş̧tir. ${ }^{[4]}$

\section{Kavus Deformitesi}

Talonaviküler subluksasyon ve sıkı plantar fasyanın uygun tedavi edilmemesi, kavovarus deformitesi ile sonuçlanır. Eğer ayak arkası yeterince mobil ise, yumuşak doku gevşetmesi yeterli olacaktır. Tersi durumda, ek kalkaneal osteotomi endikedir. ${ }^{[27]}$ Yineleyen kavus deformitesi, genellikle hafiftir ve birinci metatars başı altına uygulanacak yukarı yönlü basıdan oluşan manipülasyon ve alçılama ile düzelir. Subkutan plantar fasyotomiye, olguların sadece $\% 6$ 'sında gerek duyulur. ${ }^{[10]}$ ilk metatarsalde şiddetli plantar fleksiyon deformitesi mevcutsa, ekstansör hallusis longus ilk metatars boynuna transfer edilebilir.

\section{CERRAHI TEDAVI SONRASI YINELEME}

Cerrahi olarak düzeltilmiş olgularda, retrakte olacak bağlar kesilmiş ve tendonlar uzatılmış olsa bile, cerrahi skar dokusunun retraksiyonu ve persistan kas fibrozisi nedeniyle, deformite tekrarlayabilir (Şekil 1 ve 2). ${ }^{[28]}$ iki haftada bir değiştirilen, ayağı belirgin dış rotasyon ve maksimum dorsifleksiyonda tutan 4-6 alçı ve manipülasyon ile, orijinal düzeltme elde edilebilir. Bu tedavinin devamında, ayak bileği dorsifleksiyonu $15^{\circ}$ 'den az ise Aşil uzatılır. Alçı 3-4 hafta tutulduktan sonra, çocuk dört yaşına gelene dek, geceleri ayağı dış rotasyonda tutacak ortez kullanılır. Tibialis anterior kası ayağa güçlü bir şekilde supinasyon yaptırıyorsa, 2,5 yaştan sonra, kemikleşme çekirdeği belirginleşip tendon tutunması için yeterli hacme ulaşan üçüncü küneiforma transfer edilir. ${ }^{[1,4,10]}$ Böylece, navikula lateralize edilmemiş olsa da, küneiformun lateralize edilmesi ile ayak ön ve arka kısımlarının ilişkisi restore edilmiş olur. ${ }^{[1]}$ Mediyal naviküler deplasman tam olarak düzeltilmediğinde ve ön-arka talokalkaneal açı $20^{\circ}$ 'den az ise, supinasyon belirginleşir. Tibialis anterior tendon transferi, düzeltilmiş topuk varusunu koruyup ön-arka talokalkaneal açıyı düzelterek, mediyal gevşetme girişimi ihtiyacını belirgin şekilde azaltır. Tibialis anterior tendonu, şiddetli ayak pronasyonu ve topuk valgusuna yol açacağından, 5 . metatars ya da küboide transfer edilmemelidir.

Cerrahi sonrası ortaya çıkan ekin deformitesine, genellikle sert, deforme ve birden çok skar dokusuna sahip bir ayak - ayak bileği eşlik eder. Fikse ekin deformitesinin tedavisinde; posteromediyal gevşetme, supramalleolar osteotomi, üçlü artrodez, talektomi, llizarov tekniği ve anterior distal tibial epifizyodez tanımlanmıştır. ${ }^{[29-32]}$ Posteromediyal gevşetme, değişen anatomi ve skar dokuları nedeniyle güçtür. Talektomi bir kurtarıcı prosedürdür; artrit ankiloz ve yineleme gibi yüksek komplikasyon oranına sahiptir. ${ }^{[3]}$ Kemik prosedürleri plantigrad ayakla sonuçlanabilir, ancak kısa ve sert bir ayağa neden olur. ${ }^{[29]}$

Freedman, Ilizarov tekniği uyguladığı olguların çoğunda kötü sonuç elde etmiş ve bu yöntemin çok da 


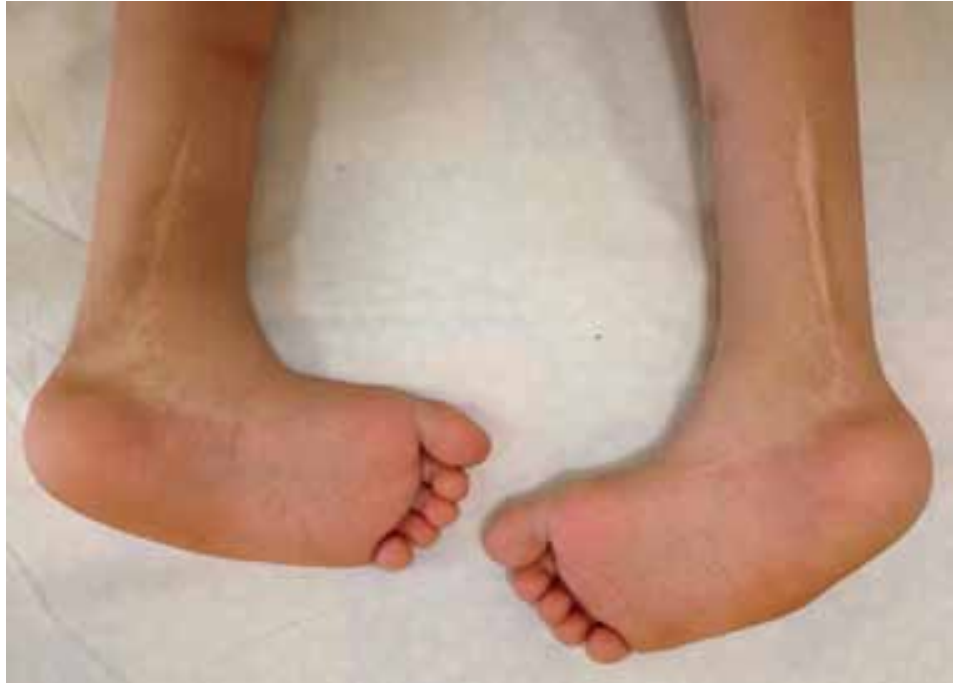

Şekil 1. Yaklaşık 4 yıl önce bilateral çarpık ayak nedeniyle posteromediyal gevşetme uygulanan hastanın tekrarlayan deformitesi.

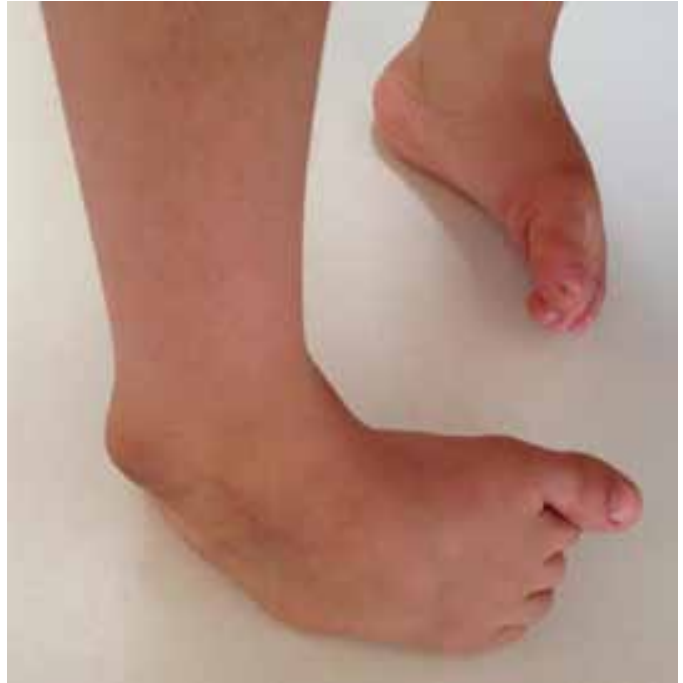

Şekil 2. Aynı hastanın ayakta basarak çekilmiş görüntüsünde daha da belirginleşen topuk varusu ve ön ayak supinasyon deformiteleri. etkili olmadığını ileri sürmüştür. ${ }^{[34]}$ Güncel Ilizarov tekniği, Ponseti'nin ardışık düzeltme tekniğini simüle eden Taylor'ın uzaysal cihazından yararlanır. ${ }^{[31]}$ Bilgisayar kontrollü olan bu yöntem, düzeltme için etkili olsa da, ayağın kısalmasını engellemediği gibi, komplikasyon hızını da azaltmaz.

\section{REZIDÜEL DEFORMITELER}

DÇA tedavisinden sonra en sık gözlenen rezidüel deformite, olguların \%95'inde ayak önü adduksiyonu ve supinasyonu iken; topukta bir miktar ekin ve varus deformitesinin ortaya çıkması, yineleme lehinedir. ${ }^{[2,10]}$ Rezidüel ayak önü adduksiyonu ve supinasyonu için en güvenilir radyolojik bulgu, ön-arka yük verme grafisindeki talo-ilk-metatarsal ve kalkaneo-beşinci-metatarsal açılardır. ${ }^{[2]}$ Normalde, metatarsal aks talar aksın lateralinde olup $0-20^{\circ}$ 'dir. Talonaviküler subluksasyon ve metatarsus varusun neden olduğu rezidüel adduksiyonda, aks talusun mediyaline kayar. Metatarsus adduktusu işaret eden bir diğer açı, normalde $80-100^{\circ}$ olan ve artışı adduktus lehine olan navikulo-metatarsal açıdır. Tedaviden önce artmış lateral tibiokalkaneal ve azalmış talokalkaneal açı varlığının, rezidüel ekinovarus riskini arttırdığı ileri sürülmüştür. ${ }^{[35]}$ Talonaviküler aşırı düzeltme ile birlikte şiddetli metatarsus varus da rezidüel adduksiyona neden olabilir. Rezidüel adduksiyon kendiliğinden düzelebilse de; mobil supinasyon deformitesi tibialis anterior transferi ile, fikse ise mediyal kolon gevşetme ve lateral kolon kısaltma ile tedavi edilir. Fikse ayak önü adduksiyonu durumunda, tedavi şekli küboidden lateral kama rezeksiyondur. ${ }^{[2,25]}$
Kemikleşme merkezi belirginleşmiş beş yaşında büyük çocuklarda, aynı anda mediyal kuneiforma uygulanacak vertikal osteotomi ve küboidden çıkartılan kamanın manipülasyonla açılan bu osteotomi hattına yerleştirilmesi ile, mediyal kolon uzunluğu da düzeltilmiş olur. Daha küçük çocuklarda ise, küboide kapalı kama osteotomisi ve trans-orta ayak rotasyon prosedürü tanımlanmıştır.

Rezidüel ya da yineleyen ekin deformitesi, kısa süreli manipülasyon ve alçı tedavisine yanıt verebilir. Ek olarak uygulanacak posteromediyal gevşetme, ayağın arka kısmının fazla düzelmesine ve sonuçta kalkaneokavus ya da kalkaneo-valgus deformitelerine neden olabilir. Kalkaneus topuk oluşturmaktansa, ayak arkasında bir miktar varus bırakmak fonksiyonel olarak daha iyidir. Daha şiddetli olgularda, gastro-soleus fasyal gevşetme ya da diğer Aşil tendon uzatma teknikleri önerilmiş̧tir. ${ }^{[36]}$ Supramalleolar osteotomi ve anterior distal tibial epifizyodezin, ekin deformitesinin düzeltilmesinde klinik değerinin olmadığı gösterilmiştir. ${ }^{[29]}$

\section{SONUÇ}

Gerçekte yinelemelerin çok az kısmı deformitenin devamı olsa da, hangi deformitenin yinelediğini tespit etmek için, cerrah ilk prosedürü dikkatlice değerlendirmelidir. Değerlendirme sonucunda, tam düzelme sonrası gerçek yineleme tespit edilmişse nörolojik bozukluklar araştırılmalıdır. ${ }^{[2,37]} \mathrm{Bu}$ olgularda, ayak haricindeki deformiteler ile ayak deformitesinin 
komponentleri, eklem hareket açıklığı ve cildin durumunun yanı sıra kas tonu, kas gücü, duyu, refleks aktivite ve yürüyüş de değerlendirilmelidir. Kemikleşme merkezlerinin küçüklüğü, multiplanar deformite varlığı ve ayağa pozisyon vermedeki zorluklar nedeniyle, radyolojik değerlendirme güçtür. ${ }^{[2,38]}$ Tecrübelerimize göre, klinik gözlem ve muayene daha önemlidir.

Her DÇA deformitesinin ve ailesinin farklı olduğunu unutmadan, tedavimizi Ponseti yönteminin kurallarına tam uyarak uygulamalıyı. Alçılama ile ancak tedavinin bir kısmının bittiğini ailelere vurgulamayı ihmal etmemeliyiz. Ortez uyum sorunlarını, olduğunda, hasta eğitimi ve değişik ortezlerle en aza indirmeliyiz.

\section{KAYNAKLAR}

1. McKay SD, Dolan LA, Morcuende JA. Treatment results of late-relapsing idiopathic clubfoot previously treated with the Ponseti method. J Pediatr Orthop 2012;32(4):406-11. CrossRef

2. Parsa A, Moghadam $\mathrm{MH}$, Jamshidi $\mathrm{MH}$. Relapsing and residual clubfoot deformities after the application of the ponseti method: a contemporary review. Arch Bone Jt Surg 2014;2(1):7-10.

3. Noh $\mathrm{H}$, Park SS. Predictive factors for residual equinovarus deformity following Ponseti treatment and percutaneous Achilles tenotomy for idiopathic clubfoot: a retrospective review of 50 cases followed for median 2 years. Acta Orthop 2013;84(2):213-7. CrossRef

4. Park SS, Kim SW, Jung BS, Lee HS, Kim JS. Selective soft-tissue release for recurrent or residual deformity after conservative treatment of idiopathic clubfoot. J Bone Joint Surg $\mathrm{Br}$ 2009;91(11):1526-30. CrossRef

5. Porecha MM, Parmar DS, Chavda HR. Mid-term results of Ponseti method for the treatment of congenital idiopathic clubfoot -(a study of 67 clubfeet with mean five year followup). J Orthop Surg Res 2011;6:3. CrossRef

6. Cooper DM, Dietz FR. Treatment of idiopathic clubfoot: a thirtyyear follow-up note. J Bone Joint Surg Am 1995;77(10):1477-89.

7. Siapkara A, Duncan R. Congenital talipes equinovarus: a review of current management. J Bone Joint Surg $\mathrm{Br}$ 2007;89(8):995-1000.

8. Morcuende JA, Abbasi D, Dolan LA, Ponseti IV. Results of an accelerated Ponseti protocol for clubfoot. J Pediatr Orthop 2005;25(5):623-6.

9. Dietz FR. Treatment of a recurrent clubfoot deformity after initial correction with the Ponseti technique. Instr Course Lect 2006;55:625-9.

10. Ponseti IV. Congenital Clubfoot. Fundamentals of Treatment, 2nd ed. New York: Oxford; 2000.

11. Farsetti P, Caterini R, Mancini F, Potenza V, Ippolito E. Anterior tibial tendon transfer in relapsing congenital clubfoot:long-term follow-up study of two series treated with a different protocol. J Pediatr Orthop 2006;26(1):83-90.

12. ElTayeby HM. Multiple tenotomies after Ponseti method for management of severe rigid clubfoot. J Foot Ankle Surg 2012;51(2):156-60. CrossRef

13. Herzenberg JE, Radler C, Bor N. Ponseti versus traditional methods of casting for idiopathic clubfoot. J Pediatr Orthop 2002;22(4):517-21.
14. Thacker MM, Scher DM, Sala DA, van Bosse HJ, Feldman DS, Lehman WB. Use of the foot abduction orthosis following Ponseti casts: is it essential? J Pediatr Orthop 2005;25(2):225-8.

15. Haft GF, Walker CG, Crawford HA. Early clubfoot recurrence after use of the Ponseti method in a New Zealand population. J Bone Joint Surg Am 2007;89(3):487-93.

16. Dobbs MB, Rudzki JR, Purcell DB, Walton T, Porter KR, Gurnett CA. Factors predictive of outcome after use of the Ponseti method for the treatment of idiopathic clubfeet. J Bone Joint Surg Am 2004;86-A:22-7.

17. Laaveg SJ, Ponseti IV. Long-term results of treatment of congenital club foot. J Bone Joint Surg Am 1980;62(1):23-31.

18. Delbrück $H$, Schaltenbrand $M$, Schröder $S$, Rauschmann $\mathrm{M}$, Schwenninger $\mathrm{C}$. Clubfoot treatment through the ages: the Ponseti method in comparison to other conservative approaches and operative procedures. Orthopade 2013;42(6):427-33. CrossRef

19. Willis RB, Al-Hunaishel M, Guerra L, Kontio K. What proportion of patients need extensive surgery after failure of the Ponseti technique for clubfoot? Clin Orthop Relat Res 2009;467(5):1294-7. CrossRef

20. Richards BS, Faulks S. A comparison of two nonoperative methods of idiopathic clubfoot correction: the Ponseti method and the French functional (physiotherapy) method. J Bone Joint Surg Am 2008;90(11):2313-21. CrossRef

21. Ferreira RC, Costa MT. Recurrent clubfoot -approach and treatment with external fixation. Foot Ankle Clin 2009;14(3):435-45. CrossRef

22. Ponseti IV. Treatment of congenital club foot. J Bone Joint Surg Am 1992;74(3):448-54.

23. Dyer PJ, Davis N. The role of the Pirani scoring system in the management of club foot by the Ponseti method. J Bone Joint Surg Br 2006;88(8):1082-4.

24. Mary P, Damsin JP, Carlioz H. Correction of equinus in clubfoot: the contribution of arthrography. J Pediatr Orthop 2004;24(3):312-6.

25. Sambandam SN, Gul A. Stress radiography in the assessment of residual deformity in clubfoot following postero-medial soft tissue release. Int Orthop 2006;30(3):210-4.

26. Stark JG, Johanson JE, Winter RB. The Heyman-Herndon tarsometatarsal capsulotomy for metatarsus adductus: results in 48 feet. J Pediatr Orthop 1987;7(3):305-10.

27. Rathjen KE. Disorders of the foot. In: Herring JA, editor. Tachdjian`s Pediatric Orthopaedics, 4th ed. Philadelphia: Elsevier; 2008:1079-94.

28. Goldner JL, Fitch RD. classification and evaluation of congenital talipes equinovarus. In: Simons GW, editor. The Clubfoot: The Present and a View of the Future. New York, NY: Springer-Verlag; 1994.

29. Al-Aubaidi Z, Lundgaard B, Pedersen NW. Anterior distal tibial epiphysiodesis for the treatment of recurrent equinus deformity after surgical treatment of clubfeet. J Pediatr Orthop 2011;31(6):716-20. CrossRef

30. Mehrafshan M, Rampal V, Seringe R, Wicart P. Recurrent club-foot deformity following previous soft-tissue release: mid-term outcome after revision surgery. J Bone Joint Surg Br 2009;91(7):949-54. CrossRef

31. Eidelman M, Katzman A, Bor N, Lamm BM, Herzenberg JE. Treatment of residual clubfoot deformities with the Taylor Spatial frame using a Ponseti sequence. Poster presented at: European Paediatric Orthopaedic Society 26th Annual Meeting; April 11-14, 2007; Sorrento, Italy. 
32. Stevens PM. Guided growth: 1933 to the present. Strat Traum Limb Recon 2006;1(1):29-35. CrossRef

33. Handelsman JE, Weinberg J. Supramalleolar wedge osteotomy: a method of correcting fixed equinus and associated deformities in children. The Foot 2005;15:33-9. CrossRef

34. Freedman JA, Watts $H$, Otsuka NY. The Ilizarov method for the treatment of resistant clubfoot: is it an effective solution? J Pediatr Orthop 2006;26(4):432-7.

35. Noh $\mathrm{H}$, Park SS. Predictive factors for residual equinovarus deformity following Ponseti treatment and percutaneous Achilles tenotomy for idiopathic clubfoot: a retrospective review of 50 cases followed for median 2 years. Acta Orthop 2013;84(2):213-7. CrossRef
36. ParkSS, Lee HS, Han SH, ParkJW, de Peralta MJ. Gastrocsoleus fascial release for correction of equinus deformity in residual or relapsed clubfoot. Foot Ankle Int 2012;33(12):1075-8. CrossRef

37. Lykissas MG, Crawford AH, Eismann EA, Tamai J. Ponseti method compared with soft-tissue release for the management of clubfoot: A meta-analysis study. World J Orthop 2013;4(3):144-53. CrossRef

38. Otremski I, Salama R, Khermosh O, Wientroub S. Residual adduction of the forefoot. A review of the Turco procedure for congenital club foot. J Bone Joint Surg Br 1987;69(5):832-4. 